\title{
Reciprocal effects of capsaicin and menthol on thermosensation through regulated activities of TRPV1 and TRPM8
}

\author{
Masayuki Takaishi $^{1,2} \cdot$ Kunitoshi Uchida $^{1,3} \cdot$ Yoshiro Suzuki $^{1,3} \cdot$ Hiroshi Matsui $^{2}$. \\ Tadashi Shimada $^{2}$ Fumitaka Fujita ${ }^{1,2} \cdot$ Makoto Tominaga ${ }^{1,3}$
}

Received: 20 June 2015/Accepted: 16 September 2015/Published online: 8 December 2015

(C) The Author(s) 2015. This article is published with open access at Springerlink.com

\begin{abstract}
Transient receptor potential vanilloid 1 (TRPV1) is activated by elevated temperature $\left(>42{ }^{\circ} \mathrm{C}\right)$, and it has been reported that cold temperature decreases capsaicin-induced TRPV1 activity. In contrast, transient receptor potential melastatin 8 (TRPM8) is activated by low temperatures and menthol, and heat stimulation suppresses menthol-evoked TRPM8 currents. These findings suggest that the effects of specific agents on TRPV1 and TRPM8 channels are intricately interrelated. We examined
\end{abstract}

Electronic supplementary material The online version of this article (doi:10.1007/s12576-015-0427-y) contains supplementary material, which is available to authorized users.

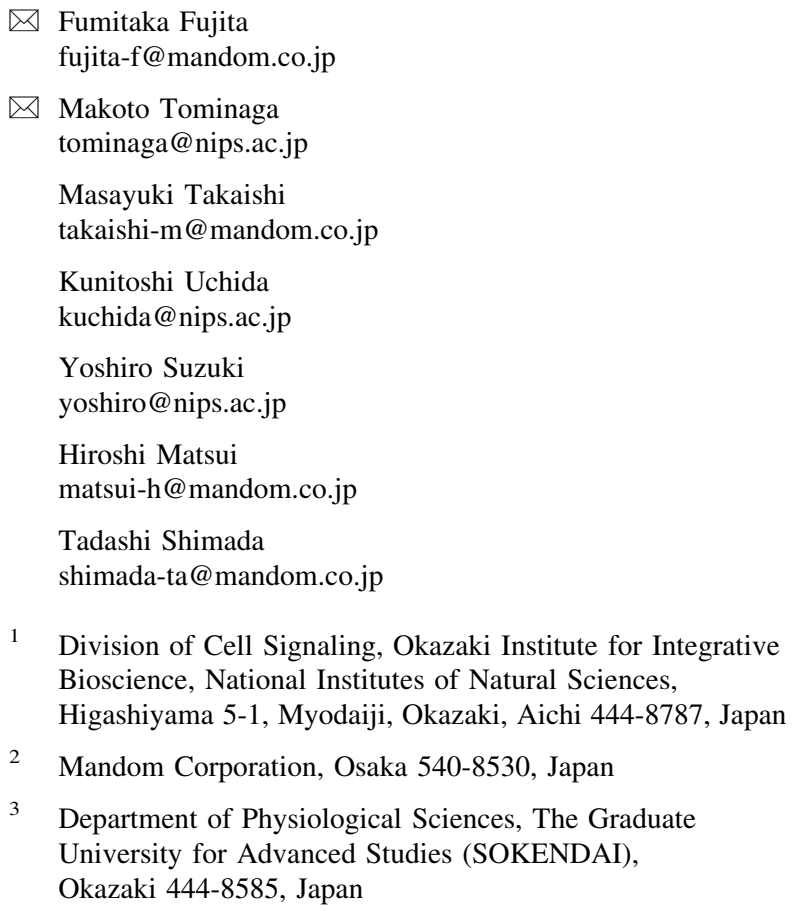

3 Department of Physiological Sciences, The Graduate University for Advanced Studies (SOKENDAI), Okazaki 444-8585, Japan

the effects of menthol on human (h)TRPV1 and of capsaicin on hTRPM8. hTRPV1 currents activated by heat and capsaicin were inhibited by menthol, whereas hTRPM8 currents activated by cold and menthol were similarly inhibited by capsaicin. An in vivo sensory irritation test showed that menthol conferred an analgesic effect on the sensory irritation evoked by a capsaicin analogue. These results indicate that in our study the agonists of TRPV1 and TRPM8 interacted with both of these channels and suggest that the anti-nociceptive effects of menthol can be partially explained by this phenomenon.

Keywords Menthol · Capsaicin · TRPV1 - TRPM8 · Analgesic

$\begin{array}{ll}\text { Abbreviations } \\ \text { HEK293T } & \text { Human embryonic kidney-derived 293T } \\ \text { TRPM8 } & \text { Transient receptor potential melastatin 8 } \\ \text { TRPV1 } & \text { Transient receptor potential vanilloid 1 } \\ \text { VBE } & \text { Vanillyl butyl ether }\end{array}$

\section{Introduction}

Transient receptor potential (TRP) channels respond to a wide variety of sensory stimuli, including temperature, nociceptive compounds, touch, osmolarity, and pheromones [1-3]. In particular, the involvement of TRP channels in thermosensation became the subject of extensive study after the cloning of the receptor of capsaicin [transient receptor potential vanilloid type 1 (TRPV1)], a pungent component of hot chili peppers [4, 5]. TRPV1 is activated by exogenous agonists (capsaicin and 
resiniferatoxin) and by physical stimuli, such as heat $\left(>42{ }^{\circ} \mathrm{C}\right)$ [6]. Transient receptor potential melastatin 8 (TRPM8), on the other hand, has been proposed to be a sensor of low temperatures in the innocuous to noxious ranges [7-10]. This channel is also activated by various cooling agents, such as menthol and icilin [7, 11, 12], by voltage $[13,14]$, and by phosphatidylinositol 4,5-bisphosphate $\left(\mathrm{PIP}_{2}\right)$ which regulates the activity of a variety of ion channels [15-18]. Approximately $10 \%$ of small-diameter sensory neurons in the rat express TRPM8 but not TRPV1 $[7,19]$, which is consistent with observations of no TRPM8 and TRPV 1 colocalization in the majority of studies using TRPM8 antibodies [20-23]. These results suggest that different nerve fibers are devoted to sensing cold and hot temperatures [24].

It has been reported that low temperatures decrease capsaicin-induced TRPV1 activation [25], whereas heat stimulation suppresses menthol-evoked current via TRPM8 [26], indicating that thermal stimulation has opposite effects on TRPV1 and TRPM8. These opposite effects suggest that input of thermal information may be regulated in a complementary manner through changes in thermosensitive TRP channel activities. As such, this notion suggests mechanisms for reciprocal effects on TRPM8 and TRPV1 in sensory systems.

Capsaicin causes heat sensation through TRPV1 activation, and menthol produces a cool sensation through TRPM8 activation; therefore, these two chemicals elicit opposite thermosensation reactions. Several other chemicals also exhibit opposing effects on the two channels; for example, ethanol [27], spermine [15, 28], and acid [6, 29, 30] inhibit TRPM8, whereas they potentiate the activity of TRPV1. Furthermore, $\mathrm{PIP}_{2}$ inhibits TRPV1 at high concentrations, whereas it activates TRPM8 [31]. These data suggest that the effects of some chemicals on the TRPV1 and TRPM8 channels intricately interact with each other. Therefore, we hypothesized that menthol and capsaicin also have inhibitory effects on TRPV1 and TRPM8, respectively, in a manner similar to thermal stimulation.

Menthol has been used for its anti-nociceptive effects for more than one thousand years [32], and preparations containing menthol are used topically to relieve neuralgia in traditional Chinese and European medicine [33]. Menthol also demonstrates some anesthetic [34-36] and $\kappa$ opioid-mediated anti-nociceptive properties in mouse hotplate tests [37]. Moreover, it has been shown that TRPM8 contributes to mediation of the effects of cold analgesia in the rat [38] and anti-nociception in mice [39]. However, the anti-nociceptive mechanisms of menthol are not yet fully understood. Since TRPV1 acts as an integrator of painful stimuli, TRPV1 antagonists can be considered as promising novel types of analgesics in therapeutic regimen [40-43].

In this study, we examined the effects of menthol on human TRPV1 (hTRPV1) and the effects of capsaicin on hTRPM8. The hTRPV1-mediated currents induced by capsaicin were inhibited by menthol in a dose-dependent manner, whereas the hTRPM8-mediated currents induced by menthol were inhibited by capsaicin in a dose-dependent manner. The results of an in vivo sensory irritation test showed that menthol conferred an analgesic effect on the sensory irritation produced by vanillyl butyl ether (VBE), a capsaicin analogue. Based on these results, we propose a new concept, namely, that capsaicin and menthol exhibit mutually opposing effects on these channels.

\section{Materials and methods}

\section{Molecular cloning}

Full-length $h T R P V 1$ and $h T R P M 8$ were obtained from Life Technologies Corp. (Carlsbad, CA). cDNAs were cloned into the pcDNA3.1 vector.

\section{Cell culture}

Human embryonic kidney (HEK) 293T cells were maintained in Dulbecco's Modified Eagle medium (DMEM; Wako Pure Chemical Industries Ltd., Osaka, Japan) supplemented with $10 \%$ fetal bovine serum (FBS; Biowest SAS, Caille, France), $100 \mathrm{U} / \mathrm{mL}$ penicillin (Life Technologies Corp.), $100 \mu \mathrm{g} / \mathrm{mL}$ streptomycin (Life Technologies Corp.), and $2 \mathrm{mM}$ L-glutamine (GlutaMAX; Life Technologies Corp.), at $37{ }^{\circ} \mathrm{C}$ in $5 \% \mathrm{CO}_{2}$. For $\mathrm{Ca}^{2+}$-imaging, $1 \mu \mathrm{g}$ of plasmid DNA containing hTRPV1 and hTRPM8 in pcDNA3 in OPTI-MEM medium (Life Technologies Corp.) was transfected into HEK293T cells using Lipofectamine Plus Reagent (Life Technologies Corp.). After a 3- to 4-h incubation, cells were reseeded on coverslips and were incubated further at $37{ }^{\circ} \mathrm{C}$ in $5 \% \mathrm{CO}_{2}$.

\section{hTRPV1 mutants and hTRPM8 mutants}

Three types of hTRPV1 mutants (Y511A, S512Y, T550I) were constructed using a modified QuickChange SiteDirected Mutagenesis method (Agilent Technologies Inc., Santa Clara, CA) [44-46], and three types of hTRPM8 mutants (Y745H, Y1005F, and L1009R) were constructed 
Table 1 Sensory irritation scores

\begin{tabular}{ccc}
\hline Sensory perception & Score & Scoring criteria \\
\hline Itching & 5 & Unbearable intense sensation \\
Slightly unusual & 4 & Distinct sensation \\
Stinging pain & 2 & Obscure sensation \\
Burning sensation & 1 &
\end{tabular}

by single amino acid substitutions using a GeneTailor SiteDirected Mutagenesis System (Invitrogen) [27, 47, 48]. The entire sequences, including the desired substitutions in the mutants, were confirmed.

\section{Calcium ion-imaging}

Calcium ion $\left(\mathrm{Ca}^{2+}\right)$-imaging was performed 1 day after transfection. HEK293T cells on coverslips were mounted in an open chamber and superfused with a standard bath solution $(140 \mathrm{mM} \mathrm{NaCl}, 5 \mathrm{mM} \mathrm{KCl}, 2 \mathrm{mM} \mathrm{MgCl} 2,2 \mathrm{mM}$ $\mathrm{CaCl}_{2}, 10 \mathrm{mM}$ HEPES, and $10 \mathrm{mM}$ glucose, $\mathrm{pH}$ 7.4). Cytosolic-free $\mathrm{Ca}^{2+}$ concentrations in HEK293T cells were measured by dual-wavelength microfluorometry using the Fura-2 radiometric indicator (Molecular Probes, Invitrogen Corp.) with excitation at $340 / 380 \mathrm{~nm}$ and emission at $510 \mathrm{~nm}$. The Fura-2 ratio image was calculated and acquired using the IP-Lab Imaging Processing system (Scanalytics Inc., Fairfax, VA, USA).

\section{Electrophysiology}

Whole-cell patch-clamp recordings were performed 1 day after transfection. The standard bath solution was the same as that used in the $\mathrm{Ca}^{2+}$-imaging experiments; extracellular $\mathrm{Ca}^{2+}$ was removed and 5 mM EGTA was added for experiments in which our aim was to determine the dose-dependent effects of menthol or capsaicin. The pipetted solution contained $140 \mathrm{mM} \mathrm{KCl}, 5 \mathrm{mM}$ EGTA, and $10 \mathrm{mM}$ HEPES, pH 7.4 (adjusted with $\mathrm{KOH}$ ). Data from the whole-cell voltage-clamp recordings were sampled at $10 \mathrm{kHz}$ and filtered at $5 \mathrm{kHz}$ for analysis (Axon 200B amplifier with pCLAMP software; Axon Instruments, Sunnyvale, CA). The membrane potential was clamped at $-60 \mathrm{mV}$ for all conditions. Voltage ramp-pulses from -150 to $+100 \mathrm{mV}$ (500 ms) were applied every $5 \mathrm{~s}$ for the inhibition of TRPV1 or TRPM8 activated by capsaicin or menthol, respectively, and every $2.5 \mathrm{~s}$ for the inhibition of TRPV1 or TRPM8 activated by temperatures or VBE, respectively.

\section{Human subjects}

Japanese male subjects $20-30$ years old were selected as participants to eliminate confounding factors that may influence the perception of sensitive skin, including race, age, gender, and hormonal and psychosocial interactions. To evaluate sensory irritation, we first randomly selected 10 of the 22 skin-sensitive male volunteers-from among a total of 49 male subjects examined who were able to discriminate the effects of menthol on the skin at between 0.05 and $0.1 \mathrm{wt} \%$ menthol. Female volunteers were excluded because of possible hormonal interactions. Informed consent was obtained from all participants, and the study was approved by the Ethical Committee of Mandom Corp.

\section{Sensory irritation tests}

The study was conducted at a temperature of $21-23{ }^{\circ} \mathrm{C}$ and a relative humidity of $45-55 \%$. The side of the neck, which is innervated by spinal nerves, was the target of the skin irritation analysis because this region is known to be sensitive to various skin irritants [49]. Prior to testing, areas of skin were cleaned with a wet towel and acclimatized for 10. Blind randomized half-region (left vs. right) trials were performed with two different samples applied to the neck region. A total of $80 \mu \mathrm{L}$ of base was applied. The subjects evaluated pricking, stinging, burning, and itching sensations after 1, 3, 5, 7, 9, and $10 \mathrm{~min}$ of compound/chemical application in accordance with the criteria summarized in Table 1 . The total sensory irritation scores were calculated for the entire period.

\section{Data analysis}

Data in all of the figures are shown as the mean \pm standard error of the mean (SEM), and $p$ values $<$ of 0.05 were considered significant. Statistical significance of effects of menthol and capsaicin on hTRPV1 and hTRPM8 mutants were evaluated using Student's $t$ test. Dose-dependent 

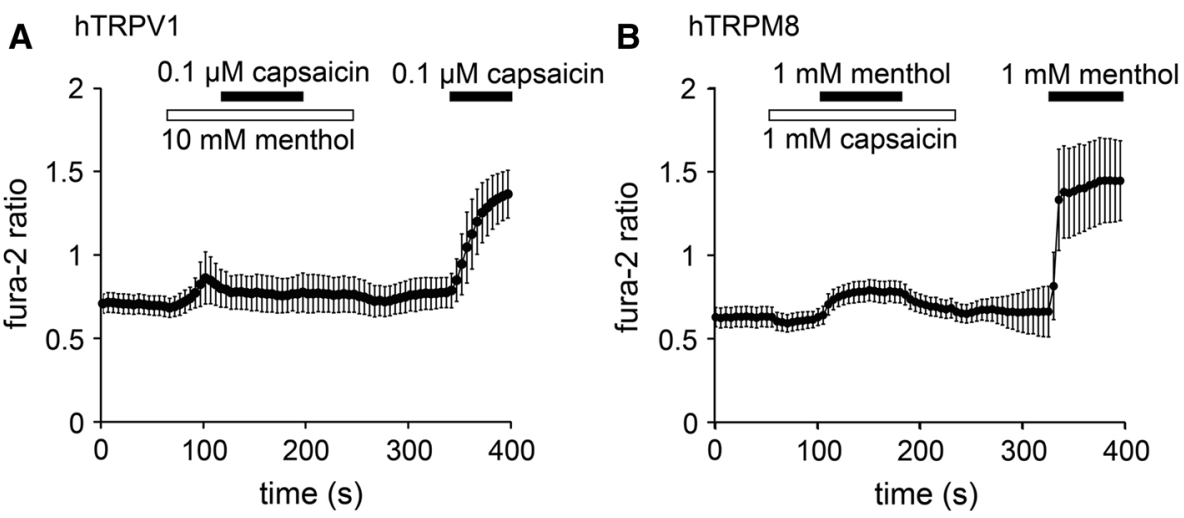

Fig. 1 Effects of menthol and capsaicin on human transient receptor potential vanilloid 1 ( $h T R P V 1$ ) or human transient receptor potential melastatin ( $h T R P M 8)$. a Changes in the Fura-2 ratio in response to capsaicin $(0.1 \mu \mathrm{M})$ application in the presence and absence of menthol $(10 \mathrm{mM})$ in human embryonic kidney (HEK) 293T cells

curves were fit with a Hill equation. Sensory irritation tests were evaluated using a Wilcoxon signed-rank test.

\section{Results}

\section{Menthol inhibited hTRPV1 activity induced by capsaicin, and capsaicin inhibited hTRPM8 activity induced by menthol}

We first examined the effects of menthol on hTRPV1 and the influence of capsaicin on hTRPM8 in HEK-derived 293T (HEK293T) cells expressing hTRPV1 or hTRPM8 using a $\mathrm{Ca}^{2+}$-imaging method at room temperature. In cells expressing hTRPV1, the changes in the Fura-2 ratios (i.e., cytosolic $\mathrm{Ca}^{2+}$ concentrations $\left[\mathrm{Ca}^{2+}\right]_{\mathrm{i}}$ ) induced by capsaicin $(0.1 \mu \mathrm{M})$ in the presence of menthol $(10 \mathrm{mM})$ were smaller than those induced in the absence of menthol (Fig. 1a). Although there was a slight increase in $\left[\mathrm{Ca}^{2+}\right]_{i}$ upon the application of menthol (10 $\mathrm{mM})$ using a patchclamp method we did not observe any current activation induced by $10 \mathrm{mM}$ menthol in the cells expressing hTRPV1 nor in the vector-transfected cells [Electronic Supplementary Material (ESM) Fig. 1a, b], indicating that the slight $\left[\mathrm{Ca}^{2+}\right]_{i}$ increase could be a non-specific phenomenon. In comparison, in cells expressing hTRPM8, changes in the Fura-2 ratios induced by menthol $(1 \mathrm{mM})$ in the presence of capsaicin $(1 \mathrm{mM})$ were smaller than those in the absence of capsaicin (Fig. 1b). Fura-2 ratios were slightly reduced by capsaicin alone in the cells expressing hTRPM8, likely because hTRPM8 was activated even at room temperature. We also confirmed that capsaicin $(1 \mathrm{mM})$ did not cause current activation in the cells expressing hTRPM8 (ESM Fig. 1c). These results suggest

expressing hTRPV1 $(n=40)$. b Changes in Fura-2 ratio in response to menthol $(1 \mathrm{mM})$ application in the presence and absence of capsaicin $(1 \mathrm{mM})$ in HEK293T cells expressing hTRPM8 $(n=94)$. Data are shown as the mean \pm standard deviation (SD)

that menthol inhibits hTRPV1 activity, whereas capsaicin inhibits hTRPM8 activity.

To confirm these possibilities, we performed patchclamp experiments using HEK293T cells expressing hTRPV1 or hTRPM8. Capsaicin $(0.1 \mu \mathrm{M})$ induced TRPV1-mediated current activation with an outwardly rectifying current-voltage (I-V) relationship revealed by ramp pulses from -150 to $+100 \mathrm{mV}$ every $5 \mathrm{~s}$. The addition of menthol $(5 \mathrm{mM})$ to the system reduced the capsaicin-evoked currents at both positive and negative potentials, and these currents were partly recovered by menthol washout (Fig. 2a). The currents evoked by concomitant application of capsaicin with menthol were smaller than those activated by capsaicin alone. The hTRPM8 currents induced by menthol $(500 \mu \mathrm{M})$ were similarly inhibited by capsaicin $(100 \mu \mathrm{M})$ in a reversible manner, and the currents evoked by concomitant application of menthol with capsaicin were smaller than those activated by menthol alone (Fig. 2b). These results are consistent with the data produced in the $\mathrm{Ca}^{2+}$-imaging experiments (Fig. 1).

We next examined the dose-dependency of the inhibitory effects. The current responses were measured in the absence of extracellular $\mathrm{Ca}^{2+}$ to minimize desensitization. Menthol inhibited $0.1 \mu \mathrm{M}$ capsaicin-activated hTRPV1 currents in a dose-dependent manner, with a half-maximal inhibitory concentration $\left(\mathrm{IC}_{50}\right)$ of approximately $1.2 \pm 0.2 \mathrm{mM}$ (Fig. 2c, e). The capsaicin-induced inhibition of menthol-activated hTRPM8 currents also occurred in a dose-dependent manner, with an $\mathrm{IC}_{50}$ of approximately $39.9 \pm 6.4 \mu \mathrm{M}$ (Fig. 2d, f). We also examined the effects of different concentrations of capsaicin on hTRPV1 in the absence and presence of $1 \mathrm{mM}$ menthol and observed an apparent shift of the capsaicin dose-dependency towards high concentrations with menthol (ESM Fig. 2). These 
A hTRPV1

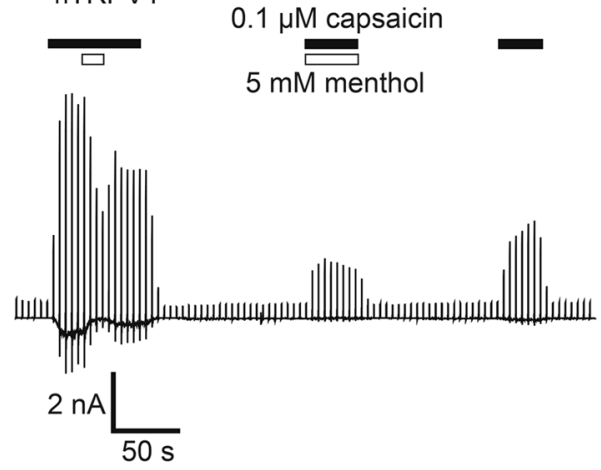

C nTRPV1

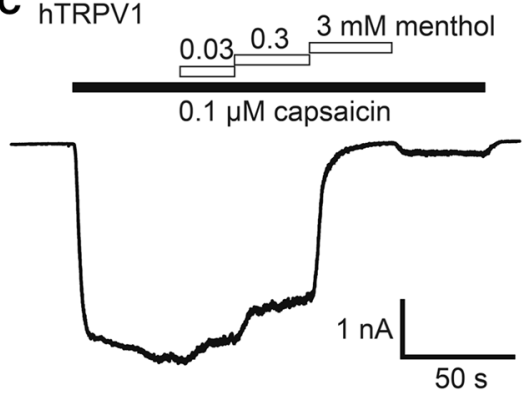

E

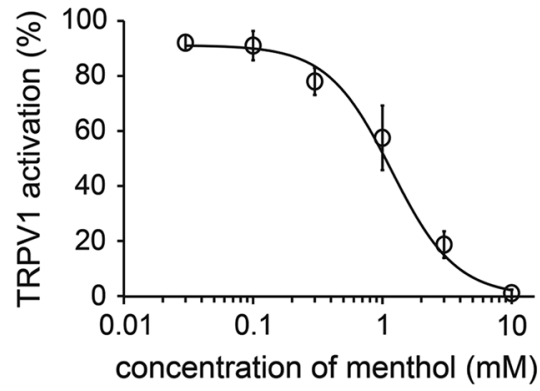

Fig. 2 Inhibition of hTRPV1-mediated currents by menthol and inhibition of hTRPM8-mediated currents by capsaicin in HEK293T cells. a A representative trace of the whole cell showing that $0.1 \mu \mathrm{M}$ capsaicin-evoked hTRPV1 currents were inhibited by menthol $(5 \mathrm{mM})$ in the presence of extracellular $\mathrm{Ca}^{2+}$. b A representative trace of the whole cell showing that $500 \mu \mathrm{M}$ menthol-evoked hTRPM8 currents were inhibited by $100 \mu \mathrm{M}$ capsaicin in the presence of extracellular $\mathrm{Ca}^{2+}$. c A representative $0.1 \mu \mathrm{M}$ capsaicin-evoked hTRPV1 current that was inhibited by menthol in a dose-dependent manner in the absence of extracellular $\mathrm{Ca}^{2+}$. d A

results indicate that menthol inhibited hTRPV1 activity and capsaicin inhibited hTRPM8 activity.

\section{Menthol and capsaicin inhibited the activation of hTRPV1 or hTRPM8 induced by thermal stimulation}

The inhibitory effects of menthol and capsaicin on hTRPV1 and hTRPM8 activities, respectively, induced by thermal stimulation were measured using a $\mathrm{Ca}^{2+}$-imaging method. To avoid the effects of desensitization during our
B

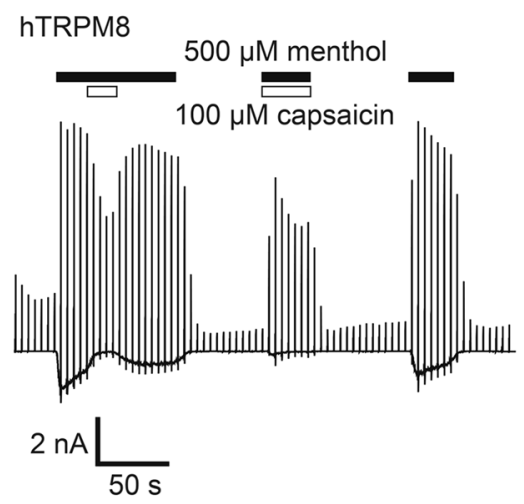

D

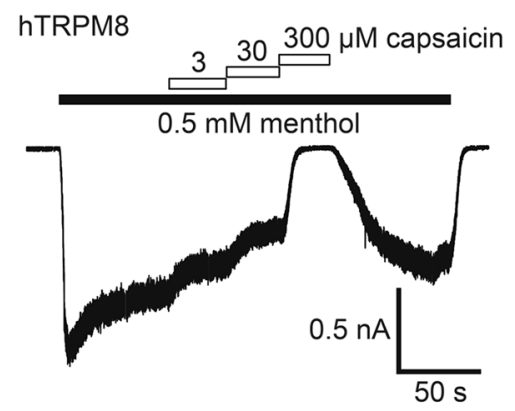

$\mathbf{F}$

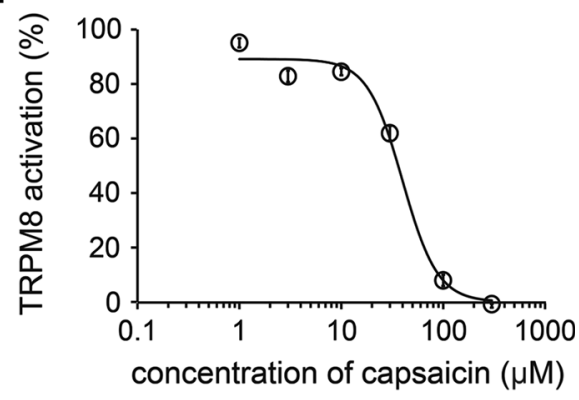

representative $0.5 \mathrm{mM}$ menthol-evoked hTRPM8 current that was inhibited by capsaicin in a dose-dependent manner in the absence of extracellular $\mathrm{Ca}^{2+}$. e Dose-dependent inhibition of $0.1 \mu \mathrm{M}$ capsaicinevoked hTRPV1 current by menthol. the half-maximal inhibitory concentration $\left(\mathrm{IC}_{50}\right)$ and Hill's coefficient values are $1.2 \pm 0.2 \mathrm{mM}$ and $1.7 \pm 0.3$, respectively $(n=5-8)$. f Dose-dependent inhibition of $0.5 \mathrm{mM}$ menthol-evoked hTRPM8 current by capsaicin; the $\mathrm{IC}_{50}$ and Hill's coefficient values are $39.9 \pm 6.4 \mu \mathrm{M}$ and $2.5 \pm 0.7$, respectively $(n=6-8)$. Data are shown as the mean \pm standard error of the mean (SEM)

investigation of the effects of menthol on heat-evoked $\left(>45^{\circ} \mathrm{C}\right)$ TRPV1-mediated $\left[\mathrm{Ca}^{2+}\right]_{\mathrm{i}}$ changes, we compared the effects in different cells. The increases in Fura-2 ratios induced by heat stimulation in the absence of menthol $(0.54 \pm 0.03)$ were significantly larger than those induced by heat stimulation in the presence of menthol $(0.35 \pm 0.02 ; p<0.01)$ (Fig. 3a, b), suggesting that menthol inhibited hTRPV1 activity induced by heat stimulation. The increases in Fura-2 ratios induced by capsaicin after heat stimulation in the presence of menthol were slow, possibly because the effects of menthol were not 
Fig. 3 Inhibition of heatevoked hTRPV1 and coldevoked hTRPM8 responses by menthol and capsaicin. a, b Changes in the Fura-2 ratio in response to heat stimulation $\left(>45^{\circ} \mathrm{C}\right.$ ) in the absence (a) and presence $(\mathbf{b})$ of menthol $(6 \mathrm{mM})$ in HEK293T cells expressing hTRPV1 $(n=61)$. c Changes in the Fura-2 ratio in response to cold stimulation $\left(<20^{\circ} \mathrm{C}\right)$ in the presence and absence of capsaicin (1 mM) in HEK293T cells expressing hTRPM8 $(n=117)$. Data are shown as the mean $\pm \mathrm{SD}$
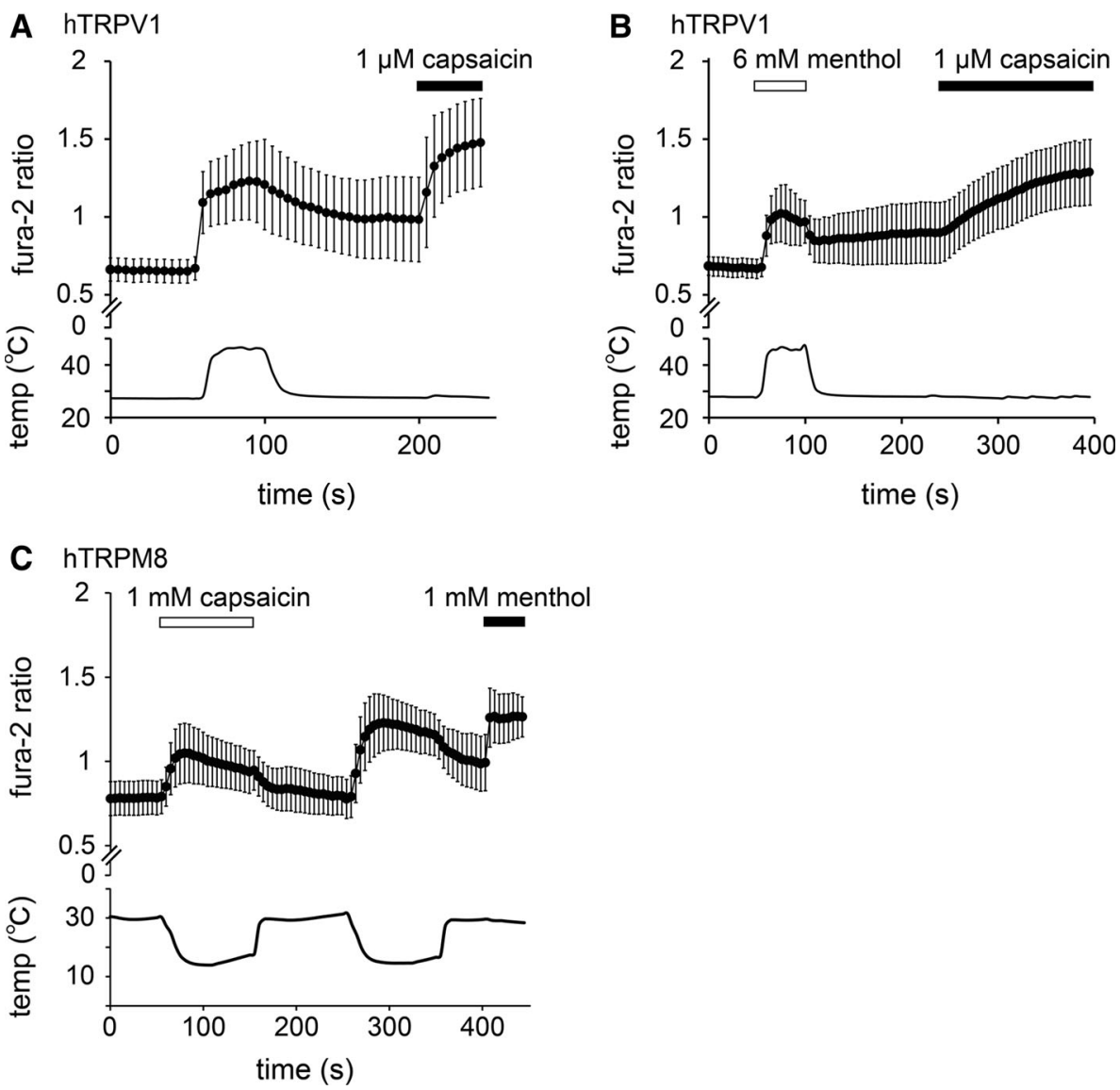

completely abolished by washout. Similarly, in cells expressing hTRPM8, $\left[\mathrm{Ca}^{2+}\right]_{i}$ increases caused by cold stimulation $\left(<20^{\circ} \mathrm{C}\right)$ in the presence of capsaicin $(1 \mathrm{mM})$ were significantly smaller than those in the absence of capsaicin $(0.19 \pm 0.01$ vs. $0.44 \pm 0.01$, respectively; $p<0.01$ ) (Fig. 3c).

In order to examine more thoroughly the inhibitory effects of menthol and capsaicin on the thermal responses of hTRPV1 and hTRPM8, respectively, we performed patch-clamp experiments with HEK293T cells expressing hTRPV1 or hTRPM8. Menthol $(5 \mathrm{mM})$ inhibited heatevoked TRPV1-mediated currents in a reversible manner (Fig. 4a). The first heat-evoked currents in the presence of menthol $(5 \mathrm{mM})$ were significantly smaller than those in the absence of menthol $(36.8 \pm 7.1$ and $123.3 \pm 35.5 \mathrm{pA} /$ $\mathrm{pF}$ in the presence and absence of menthol, respectively; $p<0.05$ ) (Fig. 4b). In a similar manner, capsaicin $(100 \mu \mathrm{M})$ inhibited the cold-evoked TRPM8-mediated currents in a reversible manner (Fig. 4c), and the first coldevoked currents in the presence of capsaicin $(100 \mu \mathrm{M})$ were significantly smaller than those in the absence of capsaicin $(3.4 \pm 0.9$ and $22.2 \pm 3.4 \mathrm{pA} / \mathrm{pF}$ in the presence and absence of capsaicin, respectively; $p<0.01$ ) (Fig. 4d). These results demonstrate that both the chemical and thermal responses of hTRPV1 and hTRPM8 were inhibited by menthol and capsaicin, respectively.

To determine whether the inhibition mediated by menthol and that mediated by capsaicin affected temperature thresholds, we then assessed changes in the temperature thresholds for hTRPV1 and hTRPM8 activation by constructing Arrhenius plots for hTRPV1-mediated and hTRPM8-mediated current responses. The temperature thresholds for hTRPV1 activation were not significantly different in the absence or presence of menthol $(41.0 \pm 1.3$ vs. $41.2 \pm 1.6^{\circ} \mathrm{C}$, respectively) (Fig. $4 \mathrm{e}-\mathrm{g}$ ). However, we were unable to generate Arrhenius plots for hTRPM8 currents because capsaicin completely inhibited cold-induced hTRPM8-mediated currents (Fig. 4c). These data indicate that menthol affected the size of the TRPV1 current without any changes the temperature thresholds for activation.

\section{The binding site of menthol in TRPV1 was distinguishable from that of capsaicin, whereas the binding site of capsaicin in TRPM8 modestly interacted with that of menthol}

Menthol activated TRPM8 and inhibited TRPV1, whereas capsaicin activated TRPV1 and inhibited TRPM8. These 
A hTRPV1

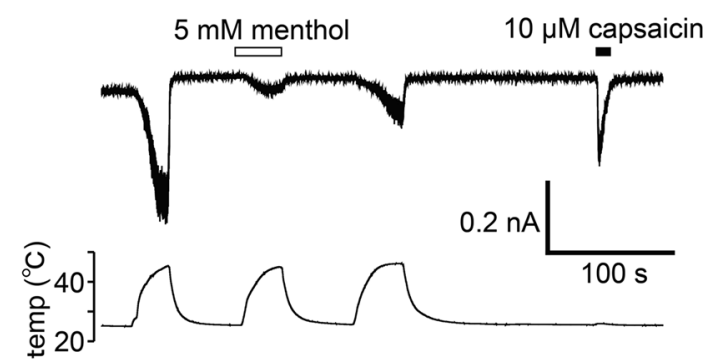

C hTRPM8
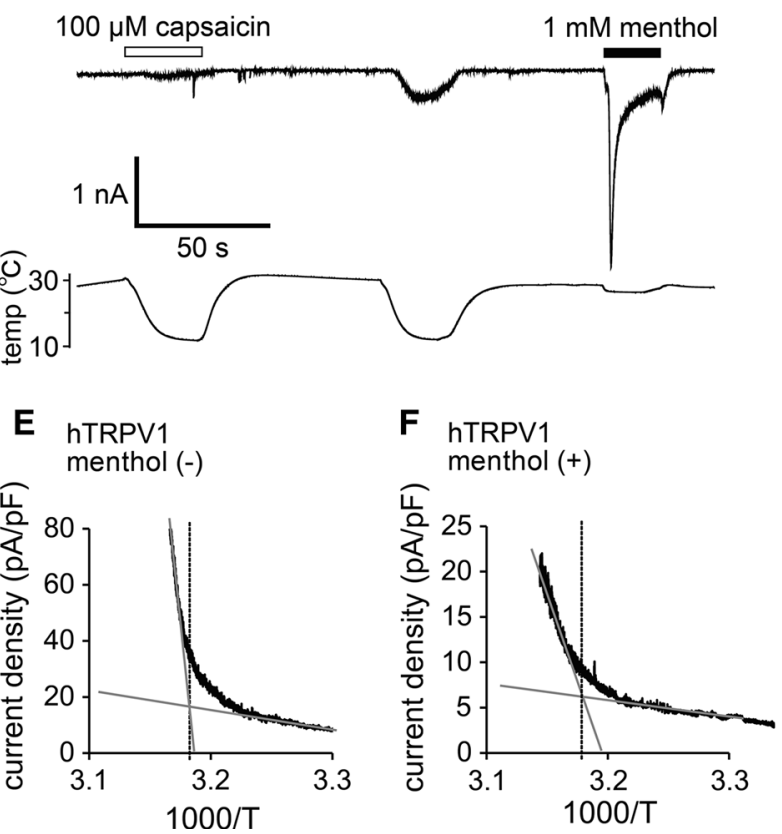

B hTRPV1

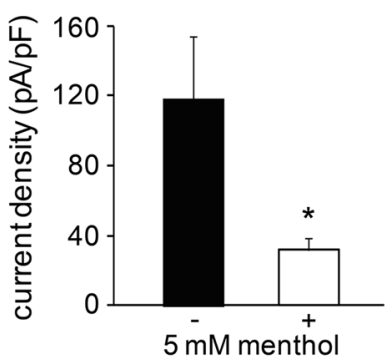

D hTRPM8

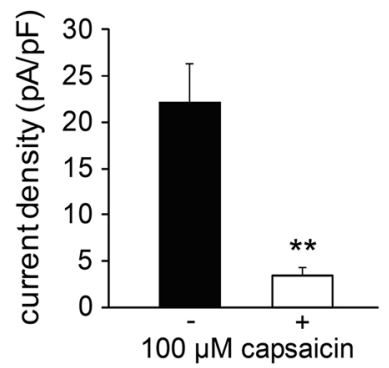

G hTRPV1 $_{1}$

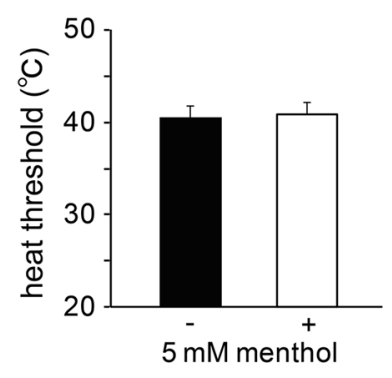

Fig. 4 Changes in thermal sensitivity of hTRPV1 and hTRPM8 by menthol and capsaicin. a A representative trace of the hTRPV1mediated heat-activated currents (upper) with changes in temperature (lower). The hTRPV1 response was confirmed by capsaicin $(10 \mu \mathrm{M})$. b Comparison of the first heat-evoked hTRPV1-mediated current densities in the absence and presence of $5 \mathrm{mM}$ menthol in HEK293T cells $(n=10-13) . * p<0.05$. c A representative trace of the hTRPM8-mediated cold-activated currents (upper) with changes in temperature (lower). The hTRPM8 response was confirmed by

results led us to hypothesize that the two compounds interact with similar sites on each channel in a competitive manner. To test this hypothesis, we examined whether menthol interacted with the same binding site as capsaicin on TRPV1 and whether capsaicin interacted with the same binding site as menthol on TRPM8. We also investigated whether menthol and capsaicin affected the heat-evoked hTRPV1 and cold-evoked TRPM8 activities, respectively, in mutant hTRPV1 and hTRPM8 channels in which capsaicin and menthol binding sites, respectively, had been mutated. Capsaicin has been reported to interact with Y511 and S512 in the cytosolic region linking transmembrane domains 2 and 3 of rat TRPV1 [44] and with T550 in the menthol $(1 \mathrm{mM})$. d Comparison of the first cold-evoked hTRPM8mediated current densities in the absence and presence of $100 \mu \mathrm{M}$ capsaicin in HEK293T cells $(n=10-12)$. $* * p<0.01$. e, f Temperature thresholds for heat-evoked hTRPV1 activation determined by Arrhenius plots from the data in the absence $\left(42.3{ }^{\circ} \mathrm{C}\right.$; e) and presence $\left(41.6{ }^{\circ} \mathrm{C}\right.$; f) of $5 \mathrm{mM}$ menthol in HEK293T cells expressing hTRPV1. g The average temperature thresholds for hTRPV1 activation after the first heat stimulation in the absence and presence of $5 \mathrm{mM}$ menthol in HEK293T cells $(n=6-7)$. Data are shown as the mean \pm SEM

transmembrane domain 4 of Oryctolagus cuniculus [45], all of which are conserved in hTRPV1 (ESM Fig. 3a). Therefore, we examined the effects of menthol on the heatevoked currents in the three hTRPV1 mutants (Y511A, S512Y and T550I) under naïve conditions. Because the heat-evoked inward currents of Y511A and S512Y mutants at $-60 \mathrm{mV}$ were very small (Fig. 5b, c, e), we examined the effects of menthol on the currents at both -60 and $+100 \mathrm{mV}$. The effects of menthol on the heat-evoked currents appeared to be larger at $-60 \mathrm{mV}$ than at $+100 \mathrm{mV}$ in the wild-type (WT) and T550I channels (Fig. 5a, d-f). Although precise comparisons in the Y511A and S512Y channels at $-60 \mathrm{mV}$ were difficult due to the 
Fig. 5 Comparison of the inhibitory effects of menthol on the currents of wild-type (WT) hTRPV1 and hTRPV1 mutants (Y511A, S512Y, T550I) expressed in HEK293T cells. ad Representative traces of the first heat-activated currents (upper) in the absence and presence of menthol $(5 \mathrm{mM})$ with temperature changes (lower) in HEK293T cells expressing WT (a), Y511A (b), S512Y (c), and T550I

(d) hTRPV1. Current-voltage relationships (right) in the absence and presence of menthol at the points indicated by asterisk in the left traces. e, f Comparison of the current densities activated by the first heat stimulation in the absence or presence of menthol $(5 \mathrm{mM})$ in HEK293T cells at $-60 \mathrm{mV}$ (e) and $+100 \mathrm{mV}$ (f). $* * p<0.01, * p<0.05$. $n=6-13$. Data are shown as the mean \pm SEM
A
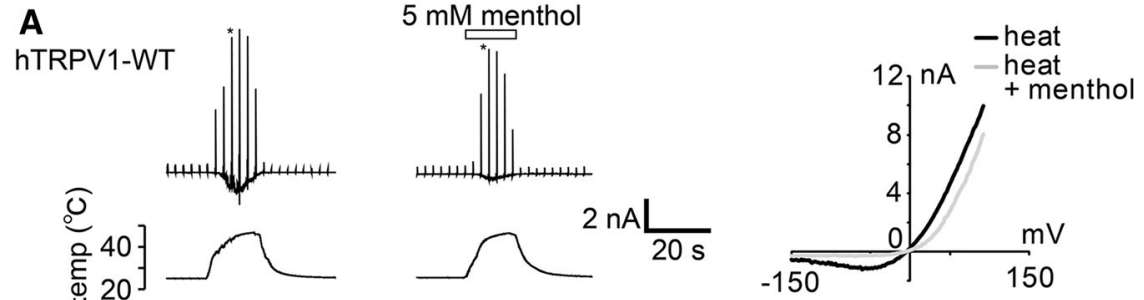

B
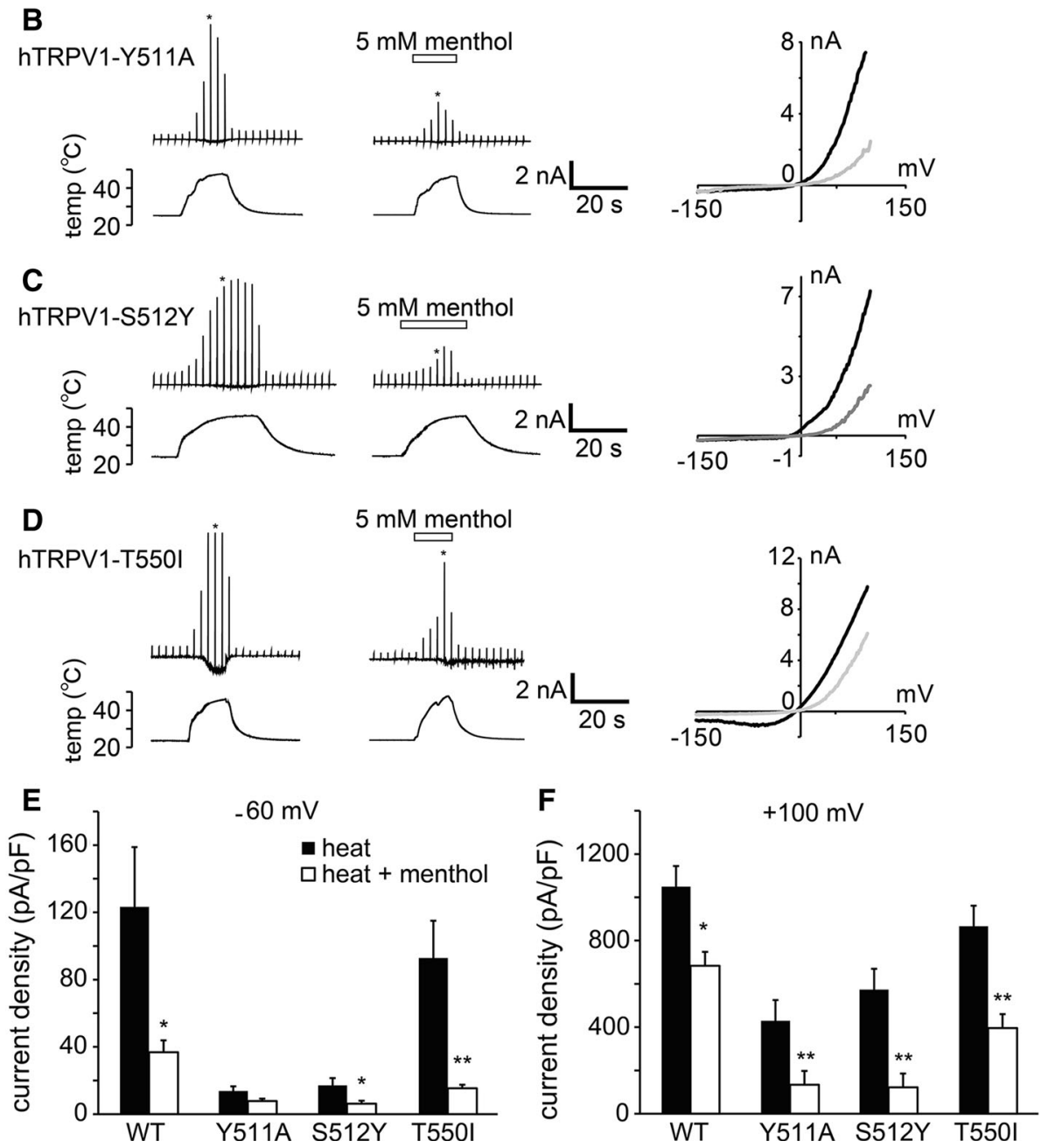

very small heat-evoked currents, menthol-induced inhibition of the mutant channels at $+100 \mathrm{mV}$ appeared to be large (Fig. 5b, c, e, f). Nonetheless, the levels of inhibition were generally similar between the WT and mutants, suggesting that a sharing of the three amino acids with capsaicin did not account for the inhibitory effects of menthol.

To the contrary, tyrosine 745 in the middle of transmembrane domain 2 has been identified as a crucial residue for the menthol sensitivity of mouse TRPM8 [48] that is conserved in hTRPM8 (ESM Fig. 3b). As already mentioned, cold-induced inward currents at $-60 \mathrm{mV}$ were very small, especially in the presence of capsaicin
(Fig. 6a-e), thereby preventing us from comparing the effects at negative potentials. However, inhibition of cold-induced TRPM8-mediated currents by capsaicin appeared smaller at $+100 \mathrm{mV}$ in the $\mathrm{Y} 745 \mathrm{H}$ mutant (Fig. 6d, f), and ratios without and with capsaicin were significantly larger in the $\mathrm{Y} 745 \mathrm{H}$ mutant $(p<0.05)$ (Fig. 6g). Cold-induced TRPM8-mediated currents became small upon washout of capsaicin (Fig. 6a), which probably reflected the inhibition of basal TRPM8-mediated currents by residual capsaicin in the cells. We examined the involvement of two other amino acids (Y1005 and L1009) that have been reported to be involved in menthol action. However, the mutants 
Fig. 6 Comparison of the inhibitory effects of capsaicin on the currents of WT hTRPM8 and hTRPM8 mutant $\mathrm{Y} 745 \mathrm{H}$ expressed in HEK293T cells. a, b Representative traces of the cold-activated currents (upper) in the absence and presence of capsaicin $(100 \mu \mathrm{M})$ with temperature changes (lower) in HEK293T cells expressing WT (a) and $\mathrm{Y} 745 \mathrm{H}$ (b). c, d Wholecell current-voltage relationships of WT (c) and $\mathrm{Y} 745 \mathrm{H}$ (d) expressed in HEK293T cells in the absence and presence of capsaicin at the points indicated by asterisk in the traces $(\mathbf{a}, \mathbf{b})$. e,

f Comparison of the current densities activated by cold in the absence and presence of capsaicin $(100 \mu \mathrm{M})$ at $-60 \mathrm{mV}$ (e) and $+100 \mathrm{mV}$ (f).

** $p<0.01 . n=8-12$. $\mathrm{g}$ Comparison of the ratios of the cold-activated currents at $+100 \mathrm{mV}$ without and with capsaicin from the data shown in f. $* * p<0.01$. Data are shown as the mean \pm SEM
A

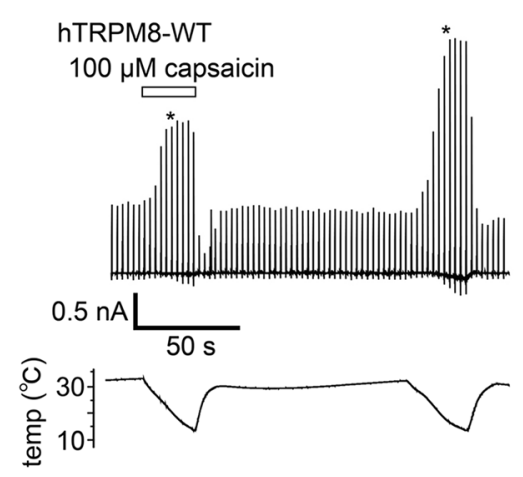

C

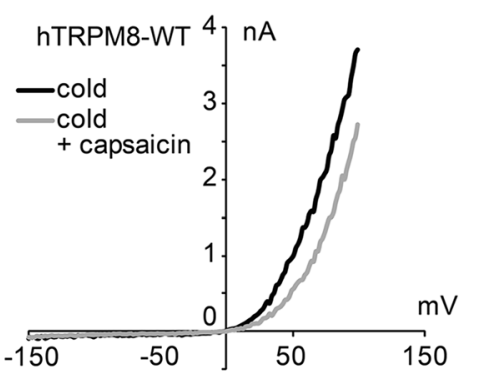

B

hTRPM8-Y745H $100 \mu \mathrm{M}$ capsaicin

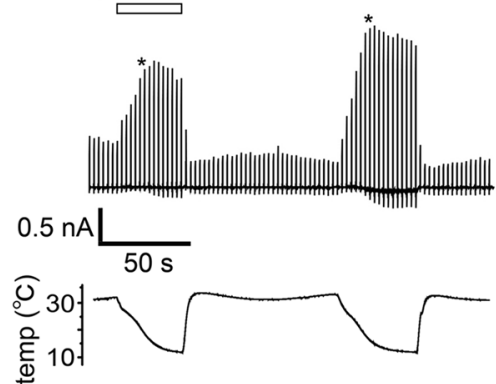

D ${ }_{\text {hTRPM8-Y745H }}$

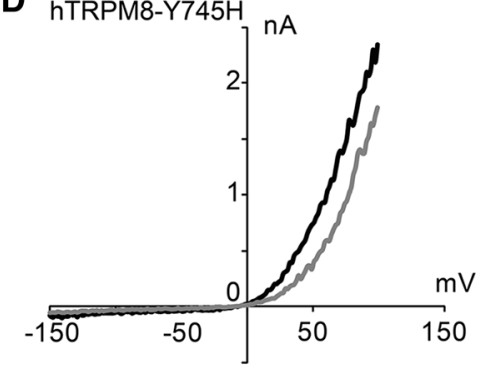

E

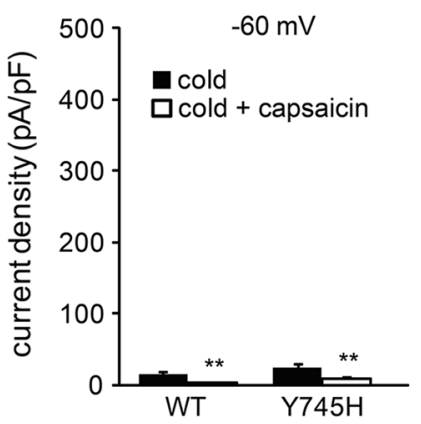

$\mathbf{F}$

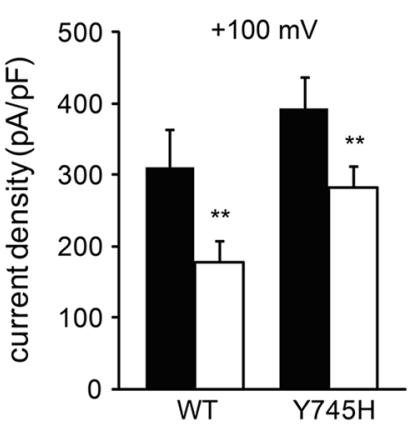

G

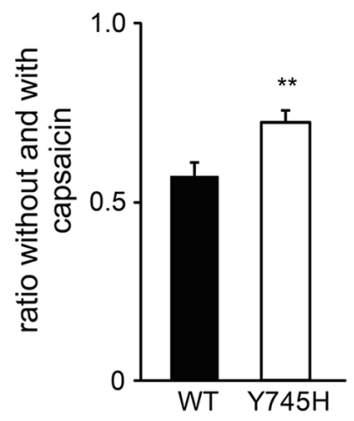

(Y1005F and L1009R) did not provide currents of sufficient strength for analysis (data not shown). These findings suggest that Y745 was involved to some extent in capsaicin-induced hTRPM8 inhibition.

\section{Menthol inhibited sensory irritation caused by an hTRPV1 agonist in vivo}

Menthol is frequently contained in topical analgesic drugs available in pharmacies, although its mechanism of action is still unknown. Based on the data shown above, we hypothesized that the analgesic effect of menthol may be through its inhibition of hTRPV1 activity. To confirm the possibility in vivo, sensitive human subjects were recruited for a sensory irritation test involving exposure to VBE, which is structurally similar to capsaicin [50]. We observed that VBE activated hTRPV1 (ESM Fig. 4a) and that this activation was inhibited by capsazepine $(1 \mu \mathrm{M})$ (ESM Fig. 4b). VBE did not cause any current activation, but rather it decreased basal currents in the vector-transfected cells (ESM Fig. 4c). We confirmed that menthol $(5 \mathrm{mM})$ inhibited the hTRPV1 activity evoked by VBE $(100 \mu \mathrm{M})$ (ESM Fig. 4d, e), suggesting that tests involving both substances together might allow us to examine the inhibitory effect of menthol on sensory irritation by VBE. We found that VBE $(0.1 \mathrm{wt} \%)$ caused sensory irritation and that this irritation gradually increased with increasing length of time after application (Fig. 7a, c). Although the VBE-induced sensory irritation scores were not reduced by concomitant application of $0.1 \mathrm{wt} \%$ menthol, they were significantly reduced by $0.3 \mathrm{wt} \%$ menthol (Fig. $7 \mathrm{a}-\mathrm{d}$ ). In human subjects, inhibition of VBE-induced irritation by menthol was smaller than the TRPV1 inhibitory effects observed in vitro. We also tested whether VBE might also activate hTRPA1 and found that VBE had a hTRPA1-activating ability, although the effects were observed only at $1 \mathrm{mM}$, whereas VBE activated hTRPV1 at lower concentrations (ESM Fig. 5). 
Fig. 7 Inhibitory effects of menthol on the Vanillyl butyl ether $(V B E)$-induced sensory irritation in humans. a, c Changes in sensory irritation scores following the application of $\operatorname{VBE}(0.1 \mathrm{wt} \%)$ in the absence and presence of menthol (a $0.1 \mathrm{wt} \%$; $0.3 \mathrm{wt} \%)$ ( $n=10$ each). b, d Total scores of sensory irritation by VBE during $10 \mathrm{~min}$ in the absence and presence of menthol (b 0.1 wt $\%$; d 0.3 wt $\%)$. $* p<0.05$. Data are shown as the mean \pm SEM
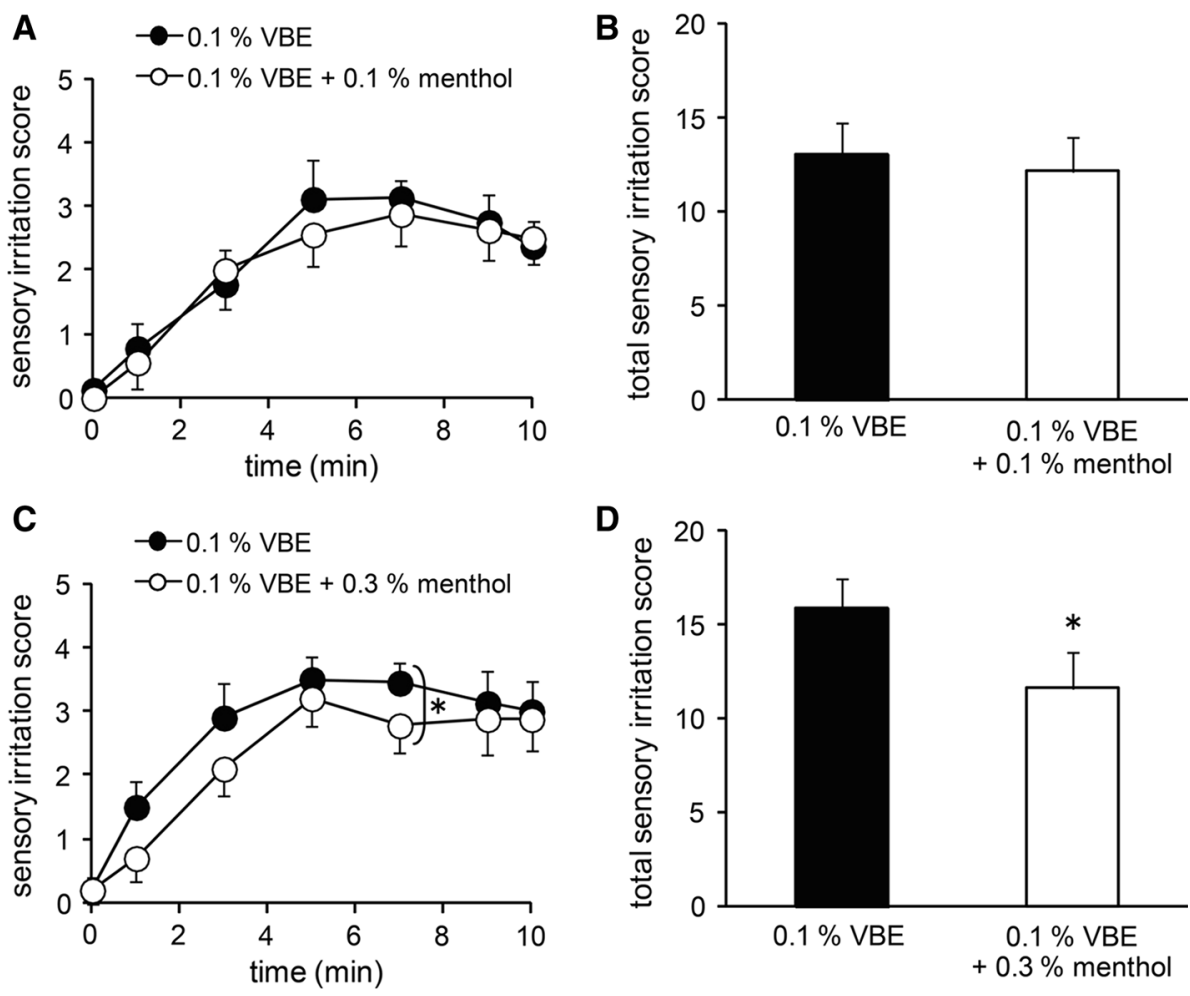

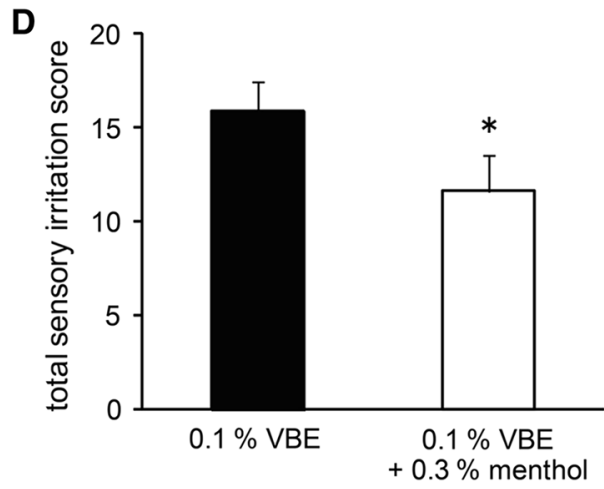

\section{Discussion}

In this study, we examined the effects of menthol on hTRPV1 and the effects of capsaicin on hTRPM8. The hTRPV1 currents induced by capsaicin were inhibited by menthol in a dose-dependent manner, and the hTRPM8 currents induced by menthol were inhibited by capsaicin in a dose-dependent manner. Our findings suggest that agonists of TRPV1 and TRPM8 exhibit mutually inhibitory effects on these channels.

In the human study, we examined whether menthol could inhibit sensory irritation caused by VBE. In the clinical setting, especially in the cosmetic research field, it is well-known that VBE causes skin irritation. Neither capsaicin nor resiniferatoxin is used for human skin studies. Surprisingly, we found that VBE activated both hTRPV1 and hTRPA1, which possibly explains the marked irritation produced by VBE when applied to humans. Our in vitro study showed that the $\mathrm{IC}_{50}$ value for menthol-induced hTRPV1 inhibition was $1.2 \pm 0.2 \mathrm{mM}$ and that it appeared that a very high level of menthol, $10 \mathrm{mM}$, completely inhibited hTRPV1 currents (Fig. 2). However, 0.3 wt $\%$ menthol, which exhibited anti-nociceptive effects in the in vivo study (Fig. 7), corresponded to $19.2 \mathrm{mM}$, which is within the attainable concentration range in clinical use $[37,38]$. Menthol is reported to cause analgesic effects through several different mechanisms, including those which are TRPM8-dependent and -independent [34-39]. Menthol also activates hTRPA1 at higher concentrations than those which activate hTRPM8 [51]. In our human study, we observed the net result of hTRPV1 activation resulting from VBE, inhibition of VBE-evoked hTRPV1 activation by menthol, menthol-evoked hTRPA1 activation, VBE-evoked hTRPA1 activation, and other mechanisms. This complicated network of mechanisms could partly explain the small inhibition of VBE-induced irritation by menthol in human subjects. Nevertheless, the observation that high concentrations of menthol $(0.3 \%)$ (which could activate hTRPA1, leading to greater irritation) inhibited VBE-induced irritation could be significant. Thus, the reduction of VBE-induced irritation by $0.3 \mathrm{wt} \%$ menthol in vivo may be partly attributable to the inhibition of hTRPV1 activity by menthol shown in the in vitro study.

Preparations containing menthol are used topically to relieve neuralgia in traditional Chinese and European medicine [33]. In addition, mint oil has been reported to alleviate thermally elicited pain and post-herpetic neuralgia, and orally applied menthol can achieve short-term analgesia [52]. Furthermore, in mice, oral or intracerebroventricular application of menthol was observed to decrease nociceptive responses in the hot-plate test and acetic acid writhing test [53]. Despite the reports on the analgesic actions of menthol in the literature, the mechanism of action has not been fully clarified, although reduced menthol-induced anti-nociception was reported in TRPM8-deficient mice [39]. Inhibition of TRPV1 by menthol, as shown in the current study, could be one of the underlying mechanisms accounting for the analgesic effects of menthol observed in rodents and 
humans. However, menthol could also exhibit its anti-nociceptive effects through activation of TRPM8 and other mechanisms, as reported earlier [37,38]. TRPV1 is activated by capsaicin as well as by heat, protons, and some endogenous substances known to be associated with tissue inflammation [4-6]. Since TRPV1 acts as an integrator of painful stimuli, TRPV1 antagonists can be viewed as promising and novel types of analgesics [40-43]. A number of potent, small TRPV1 antagonists, such as capsazepine, BCTC, CTPC, AMG9810, and SB-452533 [54-58], have advanced into clinical trials for the evaluation of their analgesic activity. Although some of these antagonists reduced noxious heat sensation, hyperthermia as a serious side effect often led to their withdrawal from the clinical trials. Thus, novel approaches to the development of anti-TRPV1 antagonists are needed, and this study shows that derivatives of menthol could be promising molecules to develop TRPV1 antagonists.

Agonists of TRPV1 and TRPM8 seem to exhibit mutual interactions for these channels. What is the physiological significance of the apparent reciprocal interaction? TRPM8 is not generally co-expressed with TRPV1 in primary afferent neurons [20-23], suggesting that the information conducted by TRPM8-expressing neurons and TRPV1-expressing neurons could influence each other. The data presented here suggest the possibility that menthol-induced TRPM8-mediated cold sensation could be enhanced by the inhibition of TRPV1 and that capsaicin-induced TRPV1-mediated heat sensation could be enhanced by the inhibition of TRPM8. The enhancement could work to strengthen the difference between TRPV1 and TRPM8 activities in some specific concentration ranges. Although we currently do not know the physiological significance of TRPM8 inhibition by capsaicin, the reciprocal interaction could lead to the enhancement of efficacious TRPV1-mediated nociceptive signals.

Acknowledgments We thank members of Division of Cell Signaling, Okazaki Institute for Integrative Bioscience for their encouragement. This work was supported by grants to MT from the Ministry of Education, Culture, Sports, Science and Technology in Japan (\#23249012).

\section{Compliance with ethical standards}

Conflict of interest The authors have no financial or other relationship that could lead to a conflict of interest. None of the authors have any competing interests.

Open Access This article is distributed under the terms of the Creative Commons Attribution 4.0 International License (http://crea tivecommons.org/licenses/by/4.0/), which permits unrestricted use, distribution, and reproduction in any medium, provided you give appropriate credit to the original author(s) and the source, provide a link to the Creative Commons license, and indicate if changes were made.

\section{References}

1. Christensen AP, Corey DP (2007) TRP channels in mechanosensation: direct or indirect activation? Nat Rev Neurosci 8:510-521

2. Minke B, Cook B (2002) TRP channel proteins and signal transduction. Physiol Rev 82:429-472

3. Zhang XF, Chen J, Faltynek CR, Moreland RB, Neelands TR (2008) Transient receptor potential A1 mediates an osmotically activated ion channel. Eur J Neurosci 27:605-611

4. Caterina MJ, Schumacher MA, Tominaga M, Rosen TA, Levine JD, Julius D (1997) The capsaicin receptor: a heat-activated ion channel in the pain pathway. Nature 389:816-824

5. Tominaga M, Caterina MJ (2004) Thermosensation and pain. J Neurobiol 61:3-12

6. Tominaga M, Caterina MJ, Malmberg AB, Rosen TA, Gilbert H, Skinner K, Raumann BE, Basbaum AI, Julius D (1998) The cloned capsaicin receptor integrates multiple pain-producing stimuli. Neuron 21:531-543

7. McKemy DD, Neuhausser WM, Julius D (2002) Identification of a cold receptor reveals a general role for TRP channels in thermosensation. Nature 416:52-58

8. Knowlton WM, Bifolck-Fisher A, Bautista DM, McKemy DD (2010) TRPM8, but not TRPA1, is required for neural and behavioral responses to acute noxious cold temperatures and cold-mimetics in vivo. Pain 150:340-350

9. Bautista DM, Siemens J, Glazer JM, Tsuruda PR, Basbaum AI, Stucky CL, Jordt SE, Julius D (2007) The menthol receptor TRPM8 is the principal detector of environmental cold. Nature 448:204-208

10. Colburn RW, Lubin ML, Stone DJ Jr, Wang Y, Lawrence D, D'Andrea MR, Brandt MR, Liu Y, Flores CM, Qin N (2007) Attenuated cold sensitivity in TRPM8 null mice. Neuron 54:379-386

11. Peier AM, Moqrich A, Hergarden AC, Reeve AJ, Andersson DA, Story GM, Earley TJ, Dragoni I, McIntyre P, Bevan S, Patapoutian A (2002) A TRP channel that senses cold stimuli and menthol. Cell 108:705-715

12. Chuang HH, Neuhausser WM, Julius D (2004) The super-cooling agent icilin reveals a mechanism of coincidence detection by a temperature-sensitive TRP channel. Neuron 43:859-869

13. Brauchi S, Orio P, Latorre R (2004) Clues to understanding cold sensation: thermodynamics and electrophysiological analysis of the cold receptor TRPM8. Proc Natl Acad Sci USA 101:15494-15499

14. Voets T, Droogmans G, Wissenbach U, Janssens A, Flockerzi V, Nilius B (2004) The principle of temperature-dependent gating in cold- and heat-sensitive TRP channels. Nature 430:748-754

15. Liu B, Qin F (2005) Functional control of cold- and mentholsensitive TRPM8 ion channels by phosphatidylinositol 4,5-bisphosphate. J Neurosci 25:1674-1681

16. Rohács T, Lopes CM, Michailidis I, Logothetis DE (2005) $\mathrm{PI}(4,5) \mathrm{P}_{2}$ regulates the activation and desensitization of TRPM8 channels through the TRP domain. Nat Neurosci 8:626-634

17. Hilgemann DW, Feng S, Nasuhoglu C (2001) The complex and intriguing lives of PIP2 with ion channels and transporters. Sci STKE 2001(111):re19

18. Chuang HH, Prescott ED, Kong H, Shields S, Jordt SE, Basbaum AI, Chao MV, Julius D (2001) Bradykinin and nerve growth factor release the capsaicin receptor from PtdIns(4,5)P2-mediated inhibition. Nature 411:957-962

19. Viana F, de la Peña E, Belmonte C (2002) Specificity of cold thermotransduction is determined by differential ionic channel expression. Nat Neurosci 5:254-260 
20. Story GM, Peier AM, Reeve AJ, Eid SR, Mosbacher J, Hricik TR, Earley TJ, Hergarden AC, Andersson DA, Hwang SW, McIntyre P, Jegla T, Bevan S, Patapoutian A (2003) ANKTM1, a TRP-like channel expressed in nociceptive neurons, is activated by cold temperatures. Cell 112:819-829

21. Kobayashi K, Fukuoka T, Obata K, Yamanaka H, Dai Y, Tokunaga A, Noguchi K (2005) Distinct expression of TRPM8, TRPA1, and TRPV1 mRNAs in rat primary afferent neurons with adelta/c-fibers and colocalization with trk receptors. J Comp Neurol 493:596-606

22. Abe J, Hosokawa H, Okazawa M, Kandachi M, Sawada Y, Yamanaka K, Matsumura K, Kobayashi S (2005) TRPM8 protein localization in trigeminal ganglion and taste papillae. Brain Res Mol Brain Res 136:91-98

23. Facer P, Casula MA, Smith GD, Benham CD, Chessell IP, Bountra C, Sinisi M, Birch R, Anand P (2007) Differential expression of the capsaicin receptor TRPV1 and related novel receptors TRPV3, TRPV4 and TRPM8 in normal human tissues and changes in traumatic and diabetic neuropathy. BMC Neurol 7:11

24. Bessou P, Perl ER (1969) Response of cutaneous sensory units with unmyelinated fibers to noxious stimuli. J Neurophysiol 32:1025-1043

25. Chung MK, Wang S (2011) Cold suppresses agonist-induced activation of TRPV1. J Dent Res 90:1098-1102

26. Wang S, Lee J, Ro JY, Chung MK (2012) Warmth suppresses and desensitizes damage-sensing ion channel TRPA1. Mol Pain 8:22

27. Benedikt J, Teisinger J, Vyklicky L, Vlachova V (2007) Ethanol inhibits cold-menthol receptor TRPM8 by modulating its interaction with membrane phosphatidylinositol 4,5-bisphosphate. J Neurochem 100:211-224

28. Ahern GP, Wang X, Miyares RL (2006) Polyamines are potent ligands for the capsaicin receptor TRPV1. J Biol Chem 281:8991-8995

29. Behrendt HJ, Germann T, Gillen C, Hatt H, Jostock R (2004) Characterization of the mouse cold-menthol receptor TRPM8 and vanilloid receptor type-1 VR1 using a fluorometric imaging plate reader (FLIPR) assay. Br J Pharmacol 141:737-745

30. Andersson DA, Chase HW, Bevan S (2004) TRPM8 activation by menthol, icilin, and cold is differentially modulated by intracellular pH. J Neurosci 24:5364-5369

31. Rohacs T, Thyagarajan B, Lukacs V (2008) Phospholipase C mediated modulation of TRPV1 channels. Mol Neurobiol 37:153-163

32. Van Hellemont J (1985) Mentha piperita. Compendium de Phytotherapie Association Pharmaceutique Belge, Brussels, pp 253-256

33. Wright A (1870) Oil of peppermint as a local anesthetic. Lancet 2464:726

34. Galeotti N, Ghelardini C, Mannelli L, Mazzanti G, Baghiroli L, Bartolini A (2001) Local anaesthetic activity of (+)- and (-)menthol. Planta Med 67:174-176

35. Gaudioso C, Hao J, Martin-Eauclaire MF, Gabriac M, Delmas P (2012) Menthol pain relief through cumulative inactivation of voltage-gated sodium channels. Pain 153:473-484

36. McKay DL, Blumberg JB (2006) A review of the bioactivity and potential health benefits of peppermint tea (Mentha piperita L.). Phytother Res 20:619-633

37. Galeotti N, Di Cesare Mannelli L, Mazzanti G, Bartolini A, Ghelardini C (2002) Menthol: a natural analgesic compound. Neurosci Lett 322:145-148

38. Proudfoot CJ, Garry EM, Cottrell DF, Rosie R, Anderson H, Robertson DC, Fleetwood-Walker SM, Mitchell R (2006) Analgesia mediated by the TRPM8 cold receptor in chronic neuropathic pain. Curr Biol 16:1591-1605
39. Dhaka A, Murray AN, Mathur J, Earley TJ, Petrus MJ, Patapoutian A (2007) TRPM8 is required for cold sensation in mice. Neuron 54:371-378

40. Gavva NR, Treanor JJ, Garami A, Fang L, Surapaneni S, Akrami A, Alvarez F, Bak A, Darling M, Gore A, Jang GR, Kesslak JP, Ni L, Norman MH, Palluconi G, Rose MJ, Salfi M, Tan E, Romanovsky AA, Banfield C, Davar G (2008) Pharmacological blockade of the vanilloid receptor TRPV1 elicits marked hyperthermia in humans. Pain 136:202-210

41. Gunthorpe MJ, Chizh BA (2009) Clinical development of TRPV1 antagonists, targeting a pivotal point in the pain pathway. Drug Discov Today 14:56-67

42. Marcello T, Arpad S (2010) Targeting TRPV1, challenges and issues in pain management. Open Drug Discov J 2:37-49

43. Marcello T, Raffaele G (2013) TRPV1 antagonists as analgesic agents. Open Pain J 6:108-118

44. Jordt SE, Julius D (2002) Molecular basis for species-specific sensitivity to "hot" chili peppers. Cell 108:421-430

45. Gavva NR, Klionsky L, Qu Y, Shi L, Tamir R, Edenson S, Zhang TJ, Viswanadhan VN, Toth A, Pearce LV, Vanderah TW, Porreca F, Blumberg PM, Lile J, Sun Y, Wild K, Louis JC, Treanor JJ (2004) Molecular determinants of vanilloid sensitivity in TRPV1. J Biol Chem 279:20283-20295

46. Shintaku K, Uchida K, Suzuki Y, Zhou Y, Fushiki T, Watanabe T, Yazawa S, Tominaga M (2012) Activation of transient receptor potential A1 by a non-pungent capsaicin-like compound, capsiate. Br J Pharmacol 165:1476-1486

47. Fujita F, Uchida K, Takaishi M, Sokabe T, Tominaga M (2013) Ambient temperature affects the temperature threshold for TRPM8 activation through interaction of phosphatidylinositol 4,5-bisphosphate. J Neurosci 33:6154-6159

48. Bandell M, Dubin AE, Petrus MJ, Orth A, Mathur J, Hwang SW, Patapoutian A (2006) High-throughput random mutagenesis screen reveals TRPM8 residues specifically required for activation by menthol. Nat Neurosci 9:493-500

49. Takaishi M, Fujita F, Uchida K, Yamamoto S, Sawada Shimizu M, Hatai Uotsu C, Shimizu M, Tominaga M (2012) 1,8-cineole, a TRPM8 agonist, is a novel natural antagonist of human TRPA1. Mol Pain 8:86

50. Mitsudome T, Matsuno T, Sueoka S, Mizugaki T, Jitsukawa K, Kaneda K (2012) Direct synthesis of unsymmetrical ethers from alcohols catalyzed by titanium cation-exchanged montmorillonite. Green Chem 14:610-613

51. Klein AH, Iodi Carstens M, McCluskey TS, Blancher G, Simons CT, Slack JP, Furrer S, Carstens E (2011) Novel menthol-derived cooling compounds activate primary and second-order trigeminal sensory neurons and modulate lingual thermosensitivity. Chem Senses 36:649-658

52. Green BG, McAuliffe BL (2000) Menthol desensitization of capsaicin irritation. Evidence of a short-term anti-nociceptive effect. Physiol Behav 68:631-639

53. Liu B, Fan L, Balakrishna S, Sui A, Morris JB, Jordt SE (2013) TRPM8 is the principal mediator of menthol-induced analgesia of acute and inflammatory pain. Pain 154:2169-2177

54. Bevan S, Hothi S, Hughes G, James IF, Rang HP, Shah K, Walpole CS, Yeats JC (1992) Capsazepine: a competitive antagonist of the sensory neurone excitant capsaicin. Br J Pharmacol 107:544-552

55. Valenzano KJ, Grant ER, Wu G, Hachicha M, Schmid L, Tafesse L, Sun Q, Rotshteyn Y, Francis J, Limberis J, Malik S, Whittemore ER, Hodges D (2003) N-(4-Tertiarybutylphenyl)-4(3-chloropyridin-2-yl)tetrahydropyrazine $-1(2 \mathrm{H})$-carbox-amide (BCTC), a novel, orally effective vanilloid receptor 1 antagonist with analgesic properties: I. In vitro characterization and pharmacokinetic properties. J Pharmacol Exp Ther 306:377-386 
56. Weil A, Moore SE, Waite NJ, Randall A, Gunthorpe MJ (2005) Conservation of functional and pharmacological properties in the distantly related temperature sensors TRVP1 and TRPM8. Mol Pharmacol 68:518-527

57. Gavva NR, Tamir R, Qu Y, Klionsky L, Zhang TJ, Immke D, Wang J, Zhu D, Vanderah TW, Porreca F, Doherty EM, Norman MH, Wild KD, Bannon AW, Louis JC, Treanor JJ (2005) AMG 9810 [(E)-3-(4-t-butylphenyl)-N-(2,3-dihydrobenzo[b] [1, 4] dioxin-6-yl)acrylamide], a novel vanilloid receptor 1 (TRPV1) antagonist with antihyperalgesic properties. J Pharmacol Exp Ther 313:474-484

58. Rami HK, Thompson M, Wyman P, Jerman JC, Egerton J, Brough S, Stevens AJ, Randall AD, Smart D, Gunthorpe MJ, Davis JB (2004) Discovery of small molecule antagonists of TRPV1. Bioorg Med Chem Lett 14:3631-3634 